\title{
The Relationship Between Health-Promoting Lifestyle Behaviors and Sleep Quality of Nurses Working in the Pediatrics Clinics
}

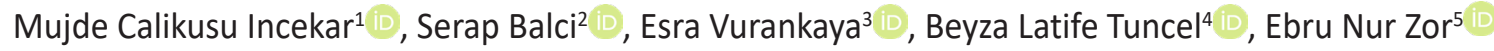 \\ ${ }^{1}$ Yuksek Ihtisas University, Faculty of Health Sciences, Department of Pediatric Nursing, Ankara, Turkey. \\ ${ }^{2}$ Istanbul University-Cerrahpasa, Florence Nightingale Faculty of Nursing, Department of Pediatric Nursing, Istanbul, Turkey. \\ ${ }^{3}$ Basaksehir Cam and Sakura City Hospital, Istanbul, Turkey. \\ ${ }^{4}$ Diskapi Yildirim Beyazit Training and Research Hospital, Ankara, Turkey. \\ ${ }^{5}$ Istanbul Training and Research Hospital, Istanbul, Turkey. \\ Correspondence Author: Mujde Calikusu Incekar \\ E-mail: mujdecalikusu@gmail.com
}

Received: $28.04 .2020 \quad$ Accepted: 19.06 .2021

\begin{abstract}
Objective: The study was conducted to determine the relationship between health-promoting lifestyle behaviors and sleep quality of nurses working in the pediatrics clinics.

Methods: The study was conducted among nurses working in the pediatrics clinic of a training and research hospital located in Istanbul. Nurse Information Form, Health-Promoting Lifestyle Profile-II (HPLP-II), and Pittsburg Sleep Quality Index (PSQI) were applied to the nurses. Ethics committee and institutional permission, permission from the scale authors via e-mail, and written consent from the nurses were obtained in the study.Besides the descriptive statistics, Mann Whitney U test, Kruskal Wallis test, and Spearman's Rho Correlation analysis were used for the analysis of the study.

Results: Among the 200 nurses that were surveyed, 121 (60.5\%) responded. $81 \%$ of the nurses ( $n=98$ ) were female, and $80.2 \%$ had a bachelor's degree. Age average of the nurses was $25.74 \pm 3.86$ years and the average weekly working hours was $49.40 \pm 7.70$ hours. It was determined that total mean score of HPLP-II was $125.26 \pm 16.40$ and PSQI total mean score was $12.13 \pm 2.29$. The lowest mean HPLP-II subscale score was $16.19 \pm 4.64$ for exercise and $17.71 \pm 3.74$ for stress management. A statistically significant correlation was found between the HPLP-II total scores and PSQI total scores $(r=-0.19 ; p<0.05)$.

Conclusion: It was determined that the health-promoting lifestyle behaviors of the nurses were above the moderate level, their sleep quality was poor, and there was a significant correlation between the health-promoting lifestyle behaviors and the sleep quality of the nurses. It can be suggested by nursing to conduct the studies determining the practices that will improve the health-promoting lifestyle behaviors of the nurses and enhance their sleep quality.

Keywords: Health Behavior, Health Promotion, Nursing, Pediatric Clinic, Sleep Quality
\end{abstract}

\section{INTRODUCTION}

The largest number of healthcare professionals in United States of America is the nurses with 4.1 million (1). According to 2018 data, it has been reported that the number of nurses in Turkey is 190.499 (2). Wellbeing and health of nurses may directly also affect the health of population along with patient care $(3,4)$. Additionally, the quality of nursing care has a direct effect on the patient health outcomes (5). Hospitalized patients need nursing care practices for 24 hours $(6,7)$.

Due to irregular shift schedules, hard work conditions such as fulfillment of physically and psychologically intense nursing tasks, low income andcontractual employment, the tendency of nurses to have a unhealthy lifestyle increases
(8) but their tendency to exhibit health-promoting behaviors decreases (9). Nutrition and exercise take place among the most studies health-promoting behaviors (10). In a study conducted with 3132 nurses, it was found that $50 \%$ of nurses did appropriate exercise and $62 \%$ consumed fast food at least twice a week (11). In a meta-analysis conducted with 145 studies, it was reported that social isolation posed a major risk factor for mortality depending on smoking and alcohol consumption (12). In the study by Etienne (13), it was found that $48 \%$ of nurses were exposed tobullying at workplace and $12 \%$ were bullied several times a week. Of the nurses, $92 \%$ had moderate and high level of stress (14). 
Due to the high level of stress, it has been found that nurses experience physical and psychological problems such as poor health $(14)$ and sleep disorders $(15,16)$. Sleep quality is an important factor allowing the nurses to get rid of the work stress, fatigue, and psychological stress. (17). It is stated that due to shift work, nurses experience sleep and mental health problems (15) and nurses reporting poor sleep quality have higher level of 10-year cardio-metabolic risks (18). The poor sleep quality of the nurses increased the malpractice rates at emergency departments (19), it was found that $64 \%$ of the nurses working in the day shift, $75.1 \%$ of those working in the evening shift, and $79.9 \%$ of those working in the night shift had poor sleep quality (20). In a study conducted with 865 nurses, nurses working in the night shift were reported to have poor sleep quality and higher depression rates (21).

Even though severalstudies for the health-promoting behaviors of the nurses have been conducted in the literature $(9,11,13,22,23)$, no study on the health-promoting behaviors of nurses working in the pediatrics clinics has been found. Also, although in the literature there are studies for the sleeping states of the nurses working at pediatric intensive care services $(24,25)$, no study examining the correlation between the health-promoting behaviors and sleeping states of the nurses working at all the pediatric clinics has been found. Thus, the aim of this study wasto determine the relationship between health-promoting lifestyle behaviors and sleep quality of the nurses working in the pediatric clinics.

\section{METHODS}

\subsection{Design and setting}

The study was conducted with descriptive-correlational design at a Training and Research Hospital in Istanbul between January and February 2019. Total number of beds in the pediatrics clinics of the hospital where the study was conducted was 183. Of these beds, 28 were at the internal medicine clinic, 22 at surgery, 78 at intensive care, 26 at emergency department, and 29 at hematology-oncology clinic.

\subsection{Sample}

The population of the study consisted of 200 nurses working in the pediatric clinic. The inclusion criteria were determined as being older than 18 years, being present at the hospital between these dates, speaking Turkish, and being voluntary to participate in the study. It was planned to include all the nurses meeting the criteria in the sample. The exact count method was used in the selection of the sample. However, the sample of the study included 121 nurses $(60.5 \%)$ since 40 nurses (20\%) were not present at the clinic between the study dates and 39 nurses (19.5\%) declined to participate in the study. The nurses were working in three shifts as $8.00 \mathrm{am}$ $-4.00 \mathrm{pm}, 4.00 \mathrm{pm}-8.00 \mathrm{am}$, and $8.00 \mathrm{am}-8.00 \mathrm{am}$.

\subsection{Measurements}

\subsubsection{Nurse Information Form}

The information form prepared by researchers for the nurses included the questions about age, gender, weekly working hours, educational background, marital status, having a child, duration of working in the pediatrics clinic, service, and status of liking the profession of nursing.

\subsubsection{The Health-Promoting Lifestyle Profile-II (HPLP-II)}

The Health-Promoting Lifestyle Profile-Il was developed by Walker et al. (26). Turkish validity and reliability study of the HPLP-II scale was conducted by Bahar et al. (27). The profile is a 4-point likert type and consists of 52 items and six factors. These factors are self-actualization, interpersonal support, nutrition, exercise, health responsibility, and stress management. In the assessment of the scale, the lowest score is $\mathbf{5 2}$ and the highest score is 208. As the total score increases, it is accepted that the individuals have more health-promoting lifestyle behaviors. Scores in every subgroup are classified in three categories. According to the scores, sub-group is divided in three categories: Weak level $(\leq 49 \%)$, moderate level (50-74\%) and good level (75 $\leq \%)$. Cronbach's alpha value of the scale was between 0.79 and 0.87 for six factors and 0.94 for overall scale (26). Cronbach's alpha value of the Turkish version of the scale was between 0.64 and 0.80 for six factors and 0.92 for overall scale (27). In the present study, Cronbach's alpha value of the scale was found between 0.63 and 0.84 for six factors and 0.89 for overall scale.

\subsubsection{The Pittsburgh Sleep Quality Index (PSQI)}

The Turkish validity and reliability study of PSQI, which was developed by Buysse et al. (28), was conducted by Ağargün et al. (29). PSQI consists of seven components as subjective sleep quality, sleep latency, sleep duration, habitual sleeping efficiency, sleep disturbances, use of sleeping medication, and daytime dysfunction. Total score of the seven components gives the total score of PSQI. Each component is scored between 0 and 3 . Total score is between 0 and 21 . High values show poor sleep quality and high level of sleep disorder. A total score of $>5$ shows that sleep quality is clinically poor (29). Cronbach's alpha value of the original version and Turkish version of the index was $0.80(28,29)$. In the present study, the Cronbach's alpha value was found as 0.79 for the overall scale.

\subsection{Procedure}

Data collection tools were applied by the researchers by conducting face-to-face meetings with the nurses. The nurses, who accepted to participate in the study completed data collection forms in a quiet and empty room for averagely 15 minutes. 


\subsection{Ethical Considerations}

Institutional permission from Provincial Directorate of Health of Istanbul (Date: 02.04.2018; No: 16867222 - 604.01.01), approval from Social and Human Sciences Research Ethics Committee of Istanbul University (Date: 08.01.2018; No: 1), permission from the scale authors via e-mail, and written consent from the nurses were obtained in the study.

\subsection{Data Analysis}

While assessing the results obtained in the study, the IBM SPSS Statistics 22 program was used for the statistical analyses. Compatibility of the variables to the normal distribution was assessed by Shapiro Wilks test, Q-Q plots, and histograms. In the data assessment, Mann Whitney $U$ test was used for the evaluations between two groups along with the descriptive statistical methods (mean, standard deviation, frequency, percentage). Kruskal Wallis test was used for the assessment of quantitative data between more than two groups. Pearson's Correlation Analysis was used for the assessment of the correlation between the scale scores. Significance was assessed at the level of $p<0.05$.

\section{RESULTS}

The study was conducted with a total of 121 nurses working in the pediatrics clinic $81 \%(n=98)$ female and $19 \%(n=23)$ male. Age average of the nurses was $25.74 \pm 3.86(\mathrm{~min}=20$; $\max =40$ ) years. Average weekly working hours of the nurses were 49.40 $\pm 7.70(\min =40 ; \max =72)$ hours.

Five nurses were only working in the $8.00 \mathrm{am}-4.00 \mathrm{pm}$ shift. Table 1 shows the sociodemographic characteristics of the nurses.

It was determined that total mean score of HPLP-II was $125.26 \pm 16.40$ and PSQItotal mean score was $12.13 \pm 2.29$. Table 2 shows subscale and total score distribution of HPLP-II and PSQI scales.

Table 3 shows the correlation assessment of the subscale and total scores of HPLP-II and PSQI.

In terms of sociodemographic characteristics, no statistically significant difference was found between the total scores of HPLP II and PSQI ( $p>0.05)$.
Table 1. Sociodemographic Characteristics of Nurses Working in Pediatrics Clinics ( $N=121)$

\begin{tabular}{|c|c|c|c|}
\hline & & $n$ & $\%$ \\
\hline \multirow{4}{*}{ Education } & High school & 10 & 8.3 \\
\hline & Associate & 5 & 4.1 \\
\hline & BSN & 97 & 80.2 \\
\hline & MSN & 9 & 7.4 \\
\hline \multirow{2}{*}{ Marital status } & Married & 33 & 27.3 \\
\hline & Single & 88 & 72.7 \\
\hline \multirow{2}{*}{ Having children } & Yes & 8 & 6.6 \\
\hline & No & 113 & 93.4 \\
\hline \multirow{4}{*}{$\begin{array}{l}\text { Working duration in the } \\
\text { pediatric clinics }\end{array}$} & $<1$ year & 26 & 21.5 \\
\hline & $1-5$ years & 86 & 71.1 \\
\hline & $6-10$ years & 5 & 4.1 \\
\hline & $11-15$ years & 4 & 3.3 \\
\hline \multirow{5}{*}{ Work unit } & Medical & 40 & 33.1 \\
\hline & Surgical & 8 & 6.6 \\
\hline & Intensive care & 39 & 32.2 \\
\hline & Emergency & 24 & 19.8 \\
\hline & $\begin{array}{l}\text { Hematology- } \\
\text { Oncology }\end{array}$ & 10 & 8.3 \\
\hline \multirow{2}{*}{ Liking the nursing profession } & Yes & 104 & 86.0 \\
\hline & No & 17 & 14.0 \\
\hline
\end{tabular}

Table 2. Distribution of Health-Promoting Lifestyle Profile-II (HPLPII), Pittsburg Sleep Quality Index (PSQI) subscale and total scores

\begin{tabular}{|c|c|c|c|}
\hline Scale & Subscale & Min - max & $M \pm S d$ \\
\hline \multirow{7}{*}{ HPLP-II } & Health responsibility & $11-32$ & $21.60 \pm 3.68$ \\
\hline & Physical activity & $8-29$ & $16.19 \pm 4.64$ \\
\hline & Nutrition & $9-31$ & $19.57 \pm 4.19$ \\
\hline & Spiritual growth & $17-35$ & $25.42 \pm 3.62$ \\
\hline & Interpersonal relationships & $16-35$ & $24.77 \pm 3.64$ \\
\hline & Stress management & $10-30$ & $17.71 \pm 3.74$ \\
\hline & Total & $88-178$ & $125.26 \pm 16.40$ \\
\hline \multirow{8}{*}{ PSQI } & Subjective sleep quality & $0-3$ & $1.36 \pm 0.92$ \\
\hline & Sleep latency & $0-3$ & $1.60 \pm 0.69$ \\
\hline & Sleep duration & $1-10$ & $6.14 \pm 1.56$ \\
\hline & Habitual sleeping efficiency & $0-2$ & $0.09 \pm 0.32$ \\
\hline & Sleep disturbances & $0-3$ & $1.30 \pm 0.56$ \\
\hline & Use of sleeping medication & $0-3$ & $1.64 \pm 0.75$ \\
\hline & Daytime dysfunction & $0-2$ & $1.07 \pm 0.83$ \\
\hline & Total & $5-17$ & $12.13 \pm 2.29$ \\
\hline
\end{tabular}


Table 3. Relationship between Health-Promoting Lifestyle Profile-II (HPLP-II), Pittsburg Sleep Quality Index (PSQI) subscale and total scores

\begin{tabular}{|c|c|c|c|c|c|c|c|}
\hline \multirow{3}{*}{ PSQI } & \multicolumn{7}{|c|}{ HPLP-II } \\
\hline & 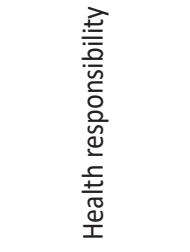 & 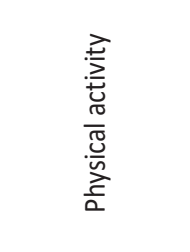 & 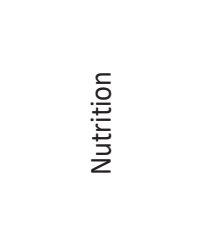 & 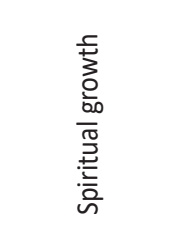 & 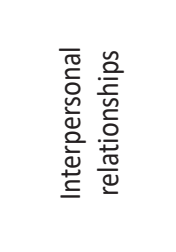 & 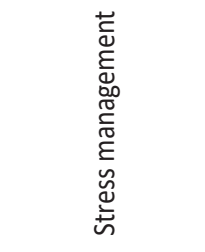 & 胥 \\
\hline & $r ; p$ & $r ; p$ & $r ; p$ & $r ; p$ & $r ; p$ & $r ; p$ & $r ; p$ \\
\hline Subjective sleep quality & $-0.078 ; 0.397$ & $-0.135 ; 0.140$ & $-0.042 ; 0.646$ & $-0.195 ; 0.032$ & $-0.037 ; 0.683$ & $-0.321 ; 0.001^{* *}$ & $-0.191 ; 0.036^{*}$ \\
\hline Sleep latency & $-0.087 ; 0.343$ & $-0.026 ; 0.779$ & $-0.019 ; 0.835$ & $0.004 ; 0.964$ & $-0.004 ; 0.968$ & $-0.152 ; 0.097$ & $-0.066 ; 0.471$ \\
\hline Sleep duration & $-0.067 ; 0.463$ & $-0.081 ; 0.377$ & $0.063 ; 0.489$ & $0.026 ; 0.778$ & $0.006 ; 0.951$ & $0.145 ; 0.113$ & $0.018 ; 0.843$ \\
\hline Habitual sleeping efficiency & $-0.147 ; 0.107$ & $-0.154 ; 0.092$ & $0.049 ; 0.597$ & $-0.063 ; 0.494$ & $0.062 ; 0.500$ & $-0.210 ; 0.021 *$ & $-0.112 ; 0.220$ \\
\hline Sleep disturbances & $0.043 ; 0.640$ & $-0.061 ; 0.508$ & $0.180 ; 0.048$ & $-0.025 ; 0.782$ & $0.071 ; 0.438$ & $-0.082 ; 0.369$ & $0.030 ; 0.745$ \\
\hline Use of sleeping medication & $-0.206 ; 0.023^{*}$ & $\begin{array}{c}-0.246 \\
0.007^{* *}\end{array}$ & $-0.295 ; 0.001^{* *}$ & $-0.042 ; 0.644$ & $-0.146 ; 0.109$ & $-0.402 ; 0.001^{* *}$ & $-0.325 ; 0.001 * *$ \\
\hline Daytime dysfunction & $-0.018 ; 0.842$ & $-0.204 ; 0.025^{*}$ & $-0.156 ; 0.087$ & $0.098 ; 0.284$ & $0.112 ; 0.22$ & $-0.234 ; 0.011^{*}$ & $-0.108 ; 0.236$ \\
\hline Total & $-0.181 ; 0.057$ & $-0.234 ; 0.011^{*}$ & $-0.026 ; 0.780$ & $-0.088 ; 0.335$ & $-0.034 ; 0.708$ & $-0.257 ; 0.004 * *$ & $-0.199 ; 0.029 *$ \\
\hline
\end{tabular}

r: Pearson Correlation analysis, ${ }^{*} p<0.05,{ }^{* *} p<0.01$

\section{DISCUSSION}

In the present study, it was found that the nurses working in the pediatrics clinics had moderate level of healthpromoting lifestyle behaviors. Similar to the present study, in the literature $(9,22,23,30)$ it was reported that the healthpromoting lifestyle behaviors of general nurses were at a moderate level. It is stated that the decrease in healthpromoting lifestyle behaviors of the nurses affects not only them but also the care of nurses, and indirectly affects the quality of nursing services, and community health (31). It is reported that the nurses know the health-promoting lifestyle behaviors, but cannot put them into practice. Insufficient time or talent or not having a strong belief may be regarded among the reasons $(32,33)$.

In the current study, the lowest health-promoting lifestyle behaviors of the nurses working in the pediatrics clinics were determined as exercise and stress management. When examining the results of the study and the studies in the literature conducted on general nurses $(9,23)$, it is seen that the lowest health-promoting lifestyle behaviors are exercise and stress management. In a study, it was reported that the nurses did not have sufficient time for exercise due to their long shifts and long monthly working hours (9). The studies have revealed that the increase in the work stress of the nurses is related to the increasing depression and lower resiliency, job satisfaction, and decreased lifestyle behavior $(34,35)$. The use of holistic approaches or mental health practices (applied awareness, cognitive training, praying, meditation, healing touch, yoga, massage, reiki, etc.) is associated withthe ability of the individual to see and care for himself as a whole and the relevant positive health effects $(36,37,38)$.
In the current study, the highest health-promoting lifestyle behaviors of the nurses working in the pediatrics clinics were determined as self-actualization and interpersonal support. When examining the results of the study and the studies in the literature conducted on general nurses $(22,23)$, it is seen that the highest health-promoting lifestyle behaviors are self-actualization and interpersonal relations. The founder of nursing, Florence Nightingale, stated in her theory that "the nurse should help the patient according to his/her vital needs and see this as the purpose of nursing" (39). The main role of nursing is care giving and the main purpose is to help the individuals and population, to find solutions for health problems, and acquire qualification for life. Moreover, profession of nursing sees human as the most valuable being and aims at providing the best quality service to humans by respecting for dignity, values, individuality, integrity, and decisions of human being $(40,41)$.

In the present study, it was determined that the nurses working in the pediatrics clinics had poor sleep quality. In a study conducted on the nurses working in the pediatric and neonatal units, it was reported that the sleep quality of the nurses was poor (24). The same result has been also found in the studies conducted on general nurses $(42,43,44,45,46)$. Changes in the sleeping habits of the nurses working in the shift system affect their sleep qualities and cause sleeping disorders by leading to difficulties in falling asleep $(43,44)$. It is reported that insufficient sleep quality is correlated with drug use $(47,48)$, occupational diseases, and work accidents (48). In a study, it was found that yoga enhanced the sleep quality and decreased the work stress (49).

In the present study, it was determined that there was a significant negative relationship the health-promoting lifestyle behaviors and sleep quality of the nurses working 
at the pediatrics clinics. Wrong adjustment of the circadian rhythm due to the shift system causes awake-asleep disorders and affects the sleep quality (50). Poor sleep quality causes fatigue because it affects the decision making process of the nurse and therefore the patient safety and thus, it is a serious issue (51). Insufficient sleep among the nurses working in shifts is correlated with insufficient self-health (52). Thus, a good sleep quality is important to increase the health and work performances of the nurses (53).

The limitations of the study may be that the study was conducted within a certain time period, the other time periods are not known, it was conducted only in a single hospital, no other hospitals were included and the sample belonged to only one institution.

\section{CONCLUSION}

In the present study, it was found that the nurses working in the pediatrics clinics had moderate level of health-promoting lifestyle behaviors. Additionally, it was determined that the nurses working in the pediatrics clinics had poor sleep quality. Following applications can be recommended in order to improve health-promoting lifestyle behaviors and sleep quality of the nurses; training programs such as undergraduate, graduate, in-service for increasing such behaviors, certificate and/or course programs, regular shift schedules, regular and sufficient rest period, workplace environments providing better conditions, follow up of these behaviors by nurse managers, and formation of protocols supporting these behaviors.Also, studies examining the effect level of such practices on the health-promoting lifestyle behaviors and sleep quality of the nurses can also be conducted.

Conflict of Interest: The authors declared no potential conflicts of interest with respect to the research, authorship, and/or publication of this article.

Funding: The authors received no financial support for the research, authorship, and/or publication of this article.

Acknowledgements: None.

\section{REFERENCES}

[1] Budden J, Zhong E, Moulton P, Cimiotti J. Highlights of the national workforce survey of registered nurses. Journal of Nursing Regulation 2013; 4(2):5-14.

[2] Republic of Turkey Ministry of Health Statistics Yearbook-2018. Republic of Turkey Ministry of Health General Directorate of Health Information Systems. Kuban Publisher: Ankara, 2019.

[3] Blake $\mathrm{H}$, Harrison $\mathrm{C}$. Health behaviours and attitudes towards being role models. British Journal of Nursing 2013; 22(2):8694.

[4] Gillen S. Unhealthy lifestyles adversely affect nurses' ability to deliver quality care. Nursing Standard 2014; 28:12.

[5] Cho E, Sloane DM, Kim EY, Kim S, Choi M, Yoo IY, Lee HS,Aiken LH. Effects of nurse staffing, work environments, and education on patient mortality: An observational study. International Journal of Nursing Studies 2015; 52(2):535-542.

[6] Ferri P, Guadi M, Marcheselli L, Balduzzi S, Magnani D, Di Lorenzo R. The impact of shift work on the psychological and physical health of nurses in a general hospital: A comparison between rotating night shifts and day shifts. Risk Management and Healthcare Policy 2016; 9:203-211.

[7] Wang ML, Tsai LJ. Work-family conflict and job performance in nurses: The moderating effects of social support. Journal of Nursing Research 2014; 22(3):200-207.

[8] Phiri LP, Draper CE, Lambert EV, Kolbe-Alexander TL. Nurses' lifestyle behaviours, health priorities and barriers to living a healthy lifestyle: a qualitative descriptive study. BMC Nursing 2014; 13:38-49.

[9] Najaf-Abadi HM, Rezaei B. Health-promoting behaviours of Iranian nurses and its relationship with some occupational factors: A cross sectional study. Journal of Nursing Management 2018; 26(6):717-725.

[10] Ross A, Bevans M, Brooks AT, Gibbons S, Wallen GR. Nurses and health - promoting behaviors: Knowledge may not translate into self-care. AORN Journal 2017; 105(3):267-275.

[11] Tucker SJ, Harris MR, Pipe TB, Stevens SR. Nurses' ratings of their health and professional work environments. Workplace Health \& Safety 2010; 58(6):253-267.

[12] Holt-Lunstad J, Smith TB, Layton JB. Social relationships and mortality risk: a meta-analytic review. PLoS Med 2010; 7(7):e1000316.

[13] Etienne E. Exploring workplace bullying in nursing. Workplace Health \& Safety 2014; 62(1):6-11.

[14] Jordan TR, Khubchandani J, Wiblishauser M. The impact of perceived stress and coping adequacy on the health of nurses: A pilot investigation. Nursing Research and Practice 2016; 1-11.

[15] Lin PC, Chen CH, Pan SM, Pan CH, Chen CJ, Chen YM, Hung HC, Wu MT. Atypical work schedules are associated with poor sleep quality and mental health in Taiwan female nurses. International Archive of Occupational and Environmental Health 2012; 85(8):877-884.

[16] Lin SH, Liao WC, Chen MY, Fan JY. The impact of shift work on nurses' job stress, sleep quality and self-perceived health status. Journal of Nursing Management 2014; 22(5):604-612.

[17] Tsuchiya M, Takahashi M, Miki K, Kubo T, Izawa S. Crosssectional associations between daily rest periods during weekdays and psychological distress, non-restorative sleep, fatigue, and work performance among information technology workers. Industrial Health 2016; 55(2):173-179.

[18] Jacobsen HB, Reme SE, Sembajwe G, Hopcia K, Stiles TC, Sorensen G,Porter JH, Marino M,Buxton OM. Work stress, sleep deficiency, and predicted 10-year cardiometabolic risk in a female patient care worker population. American Journal of Industrial Medicine 2014; 57(8):940-949.

[19] Weaver AL, Stutzman SE, Supnet C, Olson DM. Sleep quality, but not quantity, is associated with self-perceived minör error rates among emergency department nurses. International Emergency Nursing 2016; 25:48-52.

[20] Cheng SY, Lin PC, Chang YK, Lin YK, Lee PH, Chen SR. Sleep quality mediates the relationship between work-family conflicts and the self-perceived health status among hospital nurses. Journal of Nursing Management 2019; 27(2):381-387.

[21] Dai C, Qiu H, Huang Q, Hu P, Hong X, Tu J, Xie Q, Li H, Ren W, NiS, Chen F. The effect of night shift on sleep quality and 
depressive symptoms among Chinese nurses. Neuropsychiatric Disease and Treatment 2019; 15:435.

[22] Kurnat-Thoma E, El-Banna M, Oakcrum M, Tyroler J. Nurses' health promoting lifestyle behaviors in a community hospital. Applied Nursing Research 2017;35:77-81.

[23] Thacker K, Stavarski DH, Brancato V, Flay C, Greenawald D. An investigation into the health-promoting lifestyle practices of RNs. AJN The American Journal of Nursing 2016; 116(4):24-30.

[24] Guerra PC, Oliveira NF, Len CA. Sleep, quality of life and mood of nursing professionals of pediatric intensive care units. Revista da Escola de Enfermagem da USP 2016; 50(2):279-285.

[25] Puerta $Y$, García M, Heras E, López-Herce J, Fernández SN, Mencía S, CorchadoAM, ObesoRM, García-MorenoAB, JiménezB, GilE, ParedesP, PizarrosoAF, SánchezE, Calvo $M$. Sleep characteristics of the staff Working in a Pediatric intensive care Unit Based on a survey. Frontiers in Pediatrics 2017;5:288.

[26] Walker SN, Hill-Polerecky DM. Psychometric evaluation of the health-promoting lifestyle profile II. Unpublished manuscript, University of Nebraska Medical Center,1996; 120-126.

[27] Bahar Z, Beşer A, Gördes N, Ersin F,Kıssal A. Healthy life style behavior scale II: A reliability and validity study. Journal of Cumhuriyet University School of Nursing 2008; 12(1):1-13.

[28] Buysse DJ, Reynolds CF, Monk TH, Berman SR, Kupfer DJ. The Pittsburgh Sleep Quality Index: A new instrument for psychiatric practice and research. Psychiatry Research 1989; 28:193-213.

[29] Ağargün MY, Kara H,Anlar Ö. The validity and reliability of the Pittsburgh Sleep Quality Index. Turkish Journal of Psychiatry 1996; 7(2):107-115.

[30] Heidari M, Borujeni MG, Khosravizad M. Health-promoting lifestyles of nurses and its association with musculoskeletal disorders: A Cross-Sectional Study. Journal of Lifestyle Medicine 2018;8(2):72.

[31] Solidaki E, Chatzi L, Bitsios P, Markatzi I, Plana E, Castro F, Palmer $\mathrm{K}$, Coggon D,Kogevinas $\mathrm{M}$. Work related and psychological determinants of multi-site musculoskeletal pain. Scand J Work Environ Health 2010; 36:54-61.

[32] Brotons C, Björkelund C, Bulc M, Ciurana R, Godycki-Cwirko $M$, Jurgova $E$, Pullerits $L$. Prevention and health promotion in clinical practice: The views of general practitioners in Europe. Preventive Medicine 2005; 40(5):595-601.

[33] Nahm ES, Warren J, Zhu S, An M, Brown J. Nurses' self-care behaviors related to weight and stress. Nursing Outlook 2012; 60(5):e23-e31.

[34] Blake H, Mo P, Lee S, Batt M. Health in the NHS: lifestyle behaviours of hospital employees. Perspectives in Public Health 2012; 132(5):213-215.

[35] Melnyk B, Hrabe D, Szalacha L. Relationships among work stress, job satisfaction, mental health, and healthy lifestyle behaviors in new graduate nurses attending the nurse athlete program. Nursing Administration Quarterly 2013; 37(4):278-285.

[36] Anderson J, Taylor A. Effects of healing touch in clinical practice: A systematic review of randomized clinical trials. Journal of Holistic Nursing 2011; 29(3):221-228.
[37] Markwell P, Polivka B, Morris K, Ryan C, Taylor A. Snack and Relax $^{\circledR}$. A strategy to address nurses' professional quality of life. Journal of Holistic Nursing 2016; 34(1):80-90.

[38] Zeller J, Levin P. Mindfulness interventions to reduce stress among nursing personnel. Workplace Health \& Safety 2013; 61(2):85-89.

[39] Velioğlu P. Concepts and theories in nursing. Alaş Ofset: Istanbul, 1992.

[40] Babadağ K. Nursing and Values. Alter Publisher: Ankara, 2010.

[41] Can Ş, Acaroğlu R. Relation of professional values of the nurses with their individualized care perceptions. Florence Nightingale Journal of Nursing 2015;23(1):32-40.

[42] Giorgi F, Mattei A, Notarnicola I, Petrucci C, Lancia L. Can sleep quality and burnout affect the job performance of shift-work nurses? A hospital cross-sectional study. Journal of Advanced Nursing 2018; 74(3):698-708.

[43] Karakaş SA, Gönültaş N, Okanlı A. The quality of sleep of nurses who works shift workers. Journal of ERU Faculty of Health Sciences 2017; 41:17-26.

[44] Park E, Lee HY, ParkCSY. Association between sleep quality and nurse productivity among Korean clinical nurses. Journal of Nursing Management 2018; 1-8.

[45] Zdanowicz T, Turowski K, Celej-Szuster J, Lorencowicz R, Przychodzka E. Insomnia, sleepiness, and fatigue among Polish nurses. Workplace Health \& Safety 2020; 68(6):272-278.

[46] Zhang L, Sun DM, Li CB, Tao MF. Influencing factors for sleep quality among shift-working nurses: A cross-sectional study in China using 3-factor Pittsburgh sleep quality index. Asian Nursing Research 2016; 10(4):277-282.

[47] Doğan SD, SevbanArslan NA, Koparan H, Gülşen M. The quality of sleep of nurses who works shift workers. Cukurova Medical Journal 2019; 44(4):1196-1202.

[48] Shao MF, Chou YC, Yeh MY, Tzeng WC. Sleep quality and quality of life in female shift working nurses. Jornal of Advanced Nursing 2010; 66:1565-1572.

[49] Fang R, Li X. A regular yoga intervention for staff nurse sleep quality and work stress: a randomised controlled trial. Journal of Clinical Nursing 2015; 24(23-24):3374-3379.

[50] Dowling G, Mastick J. Circadian rhythm disorders. In N. S. Redeker \& G. P. McEnany (Eds.), Sleep disorders and sleep promotion in nursing practice (pp. 159-178). New York, NY: Springer, 2011.

[51] Scott LD, Arslanian-Engoren C, Engoren MC. Association of sleep and fatigue with decision regret among critical care nurses. American Journal of Critical Care 2014; 23(1):13-23.

[52] Silva-Costa A, Griep RH, Rotenberg L. Associations of a short sleep duration, insufficient sleep, and insomnia with self-rated health among nurses. PLoS One 2015; 10(5):e0126844.

[53] Chaiard J, Deeluea J, Suksatit B, Songkham W, Inta N, Stone TE. Sleep disturbances and related factors among nurses. Nursing \& Health Sciences 2019; 21(4):470-478.

How to cite this article: Calikusu Incekar M, Balci S, Vurankaya E, Tuncel BL, Zor EN. The Relationship Between Health-Promoting Lifestyle Behaviors and Sleep Quality of Nurses Working in the Pediatrics Clinics. Clin Exp Health Sci 2021; 11: 387-392. DOI: 10.33808/ clinexphealthsci.727275 